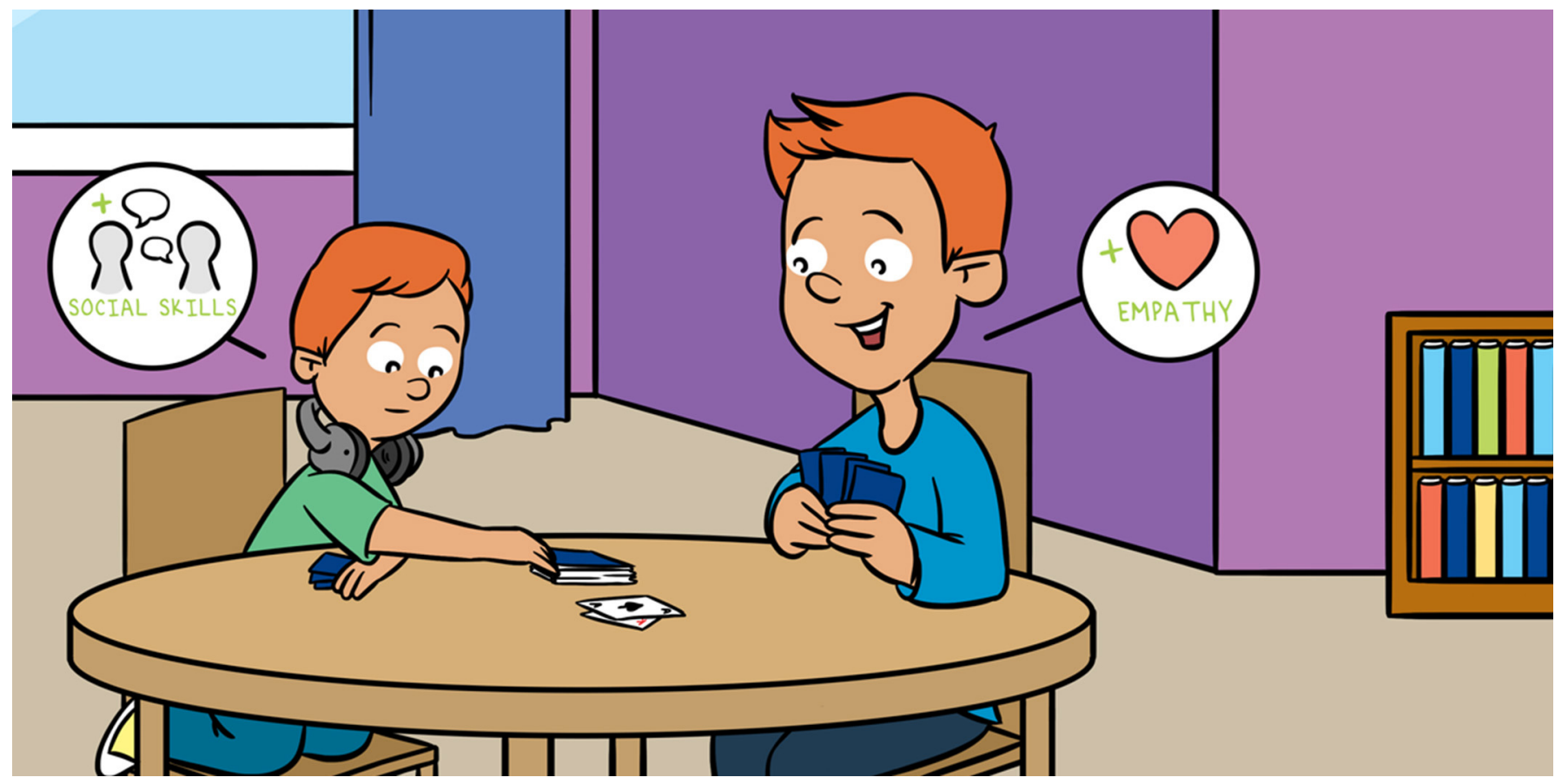

\title{
KIDS ON THE AUTISM SPECTRUM AND THEIR SIBLINGS
}

\author{
Yonat Rum ${ }^{1,2^{*}}$ and Esther Dromi ${ }^{3}$ \\ ${ }^{1}$ Psychology Department, The Hebrew University of Jerusalem, Jerusalem, Israel \\ ${ }^{2}$ Autism Research Centre, University of Cambridge, Cambridge, United Kingdom \\ ${ }^{3}$ Constantiner School of Education, Tel Aviv University, Tel Aviv, Israel
}

YOUNG REVIEWERS:
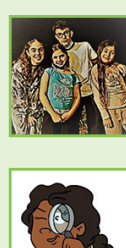
SCHECHTMAN FAMILY

AGES: 8-13

METIAV

AGE: 14

\section{SIBLINGS}

Brothers and sisters. Whoever has common parent or parents.
Siblings play and enjoy together, and also have conflicts and quarrels. This way, they teach each other important things, mostly how to communicate with others. Kids on the autism spectrum have challenges in social communication, acquiring social skills, and applying them. Therefore, many researchers were interested in negative influences that children on the autism spectrum could have on the sibling relationship in the family. Other researchers were interested in the positive aspects of these relationships. In this paper, we review aspects unique to relationships between kids on the autism spectrum and their siblings.

Siblings growing up together share mutual experiences. A sister or brother are important characters of a person's development [1]. Many skills that develop in childhood, such as language, social skills, and empathy, are influenced by siblings and sibling interactions. Through play, kids learn to cooperate, consider the feelings and the perspective of others, and activate their imaginations. Conflicts also teach kids how 
SOCIAL SKILLS

Skills allowing us to communicate and create bonds with other people.

\section{EMPATHY}

The ability to identify another person's emotions and understand them, when we know to recognize that this is someone else's emotion and not ours, and consequently feel a similar emotion ourselves.

\section{OBSERVATION}

Watching in order to test and determine conclusions. In an observation, researchers look at a phenomenon, process, or behavior, describe or measure it, and record whatever is discovered to stand up for themselves, how to protect themselves, and how to solve disagreements. The daily practice of social interactions at home can help children to get along better with friends in kindergarten or at school.

\section{HOW DO WE STUDY SIBLING RELATIONSHIPS?}

To learn about sibling relationships, researchers use various methods. One method is asking kids to answer a "self-report questionnaire," containing questions meant to measure different aspects of their relationship with their siblings. For example, how close do they feel to their brother or sister? How often do they fight? How much do they compete with each other? Kids are asked to choose the best fitting answer to each question among several options, for example (from the Sibling Relationship Questionnaire [2]):

How often do you and your sibling go together to different places and do things together?

\section{$\square$ Hardly not at all $\square$ Rarely $\square$ Somewhat $\square$ Very much Extremely much}

In self-report questionnaires, there are no right or wrong answers. Researchers are interested in learning what kids participating in the research do, think, and feel. When answers from many kids are collected, we can understand better how most kids report on their relationships with their siblings, what is the variance level between the kids, and what is common between those who answered in a specific way. Additionally, we can compare between various groups of kids; for example, we can ask whether sibling relationships in Israel are different from those of kids in other countries? What characterizes the relationships of two brothers dyads as opposed to two sisters dyads, and compared with brother and sister dyads?

Another way to learn about siblings' relationships is to ask the parents about the relationships between their kids, using a "parental report questionnaire." Such a questionnaire is particularly suitable when the kids are still too young to read and write, or maybe even cannot talk. Parental reports can teach us about the parents' perspective on the siblings' relationships, and in this case, there are also no right or wrong answers.

Another method researchers can use to learn about sibling relationships is to measure the kids' behavior directly, by performing an observation. For example, we can observe siblings playing together and count how many times during the game each of them does certain actions: expresses affection, offers help, offends or hurts, determines rules of a game; does the offended sibling "fight back" or "give up"? When do the siblings imitate each other, and how much? During 


\section{OBJECTIVE}

Not influenced by personal opinions, beliefs, or preferences; something that does not tend to one side in an argument.

\section{THE AUTISM}

SPECTRUM

Autism is a condition, influencing the way in which people grow, develop, and understand the world People on the autism spectrum have challenges with communication, learning social skills, and applying them. Many times, they are interested in specific things and focus only on them, and usually they are particularly good at observing details and patterns, and at understanding systems based on organized rules. There are people with autism who have difficulty with language, and most are very sensitive to lights, sounds, tastes, or touch. The word "spectrum" reflects the fact that these kids are very different in the types and levels of difficulty they experience, and also in their abilities and talents.

\section{COMMUNICATION}

The mutual process that includes the ability to create and transfer a message which the other can understand, and understand a message which was intentionally created by another.

Communication can be verbal or non-verbal. observations, we identify and measure behaviors which another person, who does not know the siblings, can see, and therefore this method can be more objective than self-report or parental report. On the other hand, an observation occurs at a particular time and space, while questionnaires are designed to measure what occurs usually. Self-report can also provide information about kids' feelings and thoughts which cannot always be identified by observing their behavior.

Using these and other research methods, information is gathered over many years. Here are some important things that researchers learned about sibling relationships: siblings all over the world experience feeling of closeness and affection toward each other, and also compete in different fields, especially for the attention of their parents. Siblings fight with each other and also play together. Usually, at young ages, the older brother or sister determines the rules of the game, and younger siblings tend to imitate the behavior of the older ones. But, when siblings grow up, the siblings' relationship becomes more equal. Young siblings are also influencing the growth and learning of their older siblings. For example, older sisters and brothers' development is influenced by the need to consider their younger siblings needs and perspectives, and by caring and nurturing them.

\section{KIDS ON THE AUTISM SPECTRUM AND THEIR SIBLINGS}

Like all kids, boys and girls on the autism spectrum feel various feelings. Sometimes, kids or adults find it hard to understand the feelings and thoughts of kids on the autism spectrum, and sometimes these kids find it hard to understand the feelings and thoughts of other kids or adults. It could be frustrating not to understand others, or be understood by others. Many times, kids on the autism spectrum want to acquire new friends, but find it difficult. Therefore, they receive support from professionals such as speech therapists, psychologists, and occupational therapists. They are able to learn and practice areas they find difficult, and become better at tasks that are challenging for them. Other children in the kindergarten or class can also improve their own abilities in playing with kids on the autism spectrum when they receive support to better understand others who might have different minds and experiences.

Due to the challenges kids on the autism spectrum face in communication and social interactions, it is reasonable to think that they will also have difficulties when it comes to communication with their siblings, and that the sibling relationship will be harmed. Siblings of kids on the autism spectrum might feel sadness or stress due to the ways in which others respond toward someone who is different, like their siblings. Many researchers in the field have focused on negative influences of autism on siblings and the sibling relationships. In some studies, it was found that siblings of children on the autism 
spectrum have negative feelings about their siblings' autism. It was also found that children and parents report less closeness in the siblings' relationships when one of them was on the autism spectrum, compared with typical relationships between siblings. In other studies, no such negative influences were found $[3,4]$. Many siblings of kids on the autism spectrum say that they love their siblings, play and fight with them, as usually happens between siblings. As more knowledge is accumulated in studies on autism, there are more researchers interested in studying the positive aspects in the relationships between these kids and their siblings.

The different methods researchers use to study sibling relationships could also lead to different conclusions. For example, in a study conducted in Tel Aviv University, Rum et al. [5] studied sibling relationships in families where there was a boy or girl on the autism spectrum, compared with families where siblings did not have autism. When the researchers asked the mothers to report on the relationships between their kids, there were many differences between the two groups. Mothers with a child on the autism spectrum reported less warmth and closeness between their kids and fewer conflicts and quarrels, compared with mothers whose kids are not on the autism spectrum. However, when researchers asked the kids themselves, there were not many differences between the two groups, and both reported similarly on feelings of warmth and closeness, alongside conflicts. Siblings of kids on the autism spectrum did report less intimacy, meaning, less sharing of emotions, experiences, and secrets among the siblings. This intimacy is possibly missing for siblings of kids on the autism spectrum. The researchers used another research method, an "open interview," and asked siblings of kids on the autism spectrum to tell in their own words what they think about their brother or sister, and the relationship between them. Analyzing the children's answers, the researchers noticed that all participants, apart from one kid, did not use the words "autism" or "autism spectrum" when talking about their siblings. There could be different reasons for that, like shame, or lack of knowledge. On the other hand, it is possible that siblings did not think it was an important detail to mention. What do you think?

Researchers claim that in families with kids on the autism spectrum it is important to notice whether siblings know what autism is and the characteristics of the condition. Do they know that their brother or sister is on the autism spectrum? Are they comfortable talking about it? It is worthwhile for siblings of kids on the autism spectrum to share their feelings with someone. When parents and other adults know better how siblings of kids on the autism spectrum feel, maybe they will also know how to better support them and help them enjoy a relationship with more sharing and intimacy (Figure 1). 
Figure 1

Siblings sharing a secret. Illustration: Ori Rum Zemet.

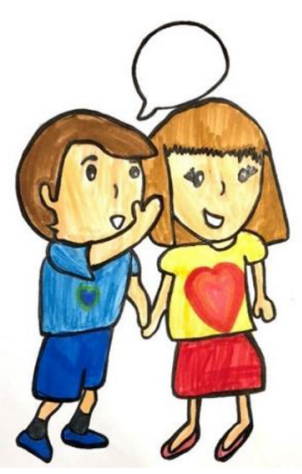

Figure 1

\section{SIBLINGS CAN LEARN FROM EACH OTHER}

An Israeli study found that kids on the autism spectrum who have an older brother or sister demonstrated higher levels of social skills compared with kids on the autism spectrum who grew without a brother or sister [6]. This might be explained by the fact that playing together (and having conflicts) with their siblings allows kids on the autism spectrum to learn and practice social and communication skills [7]. In these cases, it seems that the relationship between siblings is very similar to a typical sibling relationship, where the older siblings lead the interaction, and the younger ones learn from them. Children on the autism spectrum with younger siblings can also play with their brothers or sisters and practice social skills.

Siblings of kids on the autism spectrum might be more developed in their empathic abilities [8], and they also say that they learn a lot, thanks to the special abilities and talents of their siblings.

\section{SUMMARY}

To summarize, we know that in relationships between kids on the autism spectrum and their siblings there are unique difficulties and challenges. On the other hand, these relationships are similar to typical sibling relationships, more so than what researchers used to think, and there seem to be differences between the way in which parents and their kids describe the sibling relationship when one sibling is on the autism spectrum. One way or the other, kids on the autism spectrum and their siblings have a lot to learn and gain from each other.

We still do not know many things about sibling relationships in families of kids on the autism spectrum. For example, we (the authors of this paper) do not know of any study which tested relationships between siblings who are both on the autism spectrum, compared with those in which only one sibling is on the autism spectrum. This is a very 
interesting research question for researchers who would like to design additional studies on this topic.

If you are on the autism spectrum and you do not have brothers or sisters, do not worry at all! You can play (and fight) with friends or cousins, for example. This will contribute to the improvement of your social skills, and will also contribute a lot to those you play with.

\section{REFERENCES}

1. McHale, S. M., Updegraff, K. A., and Whiteman, S. D. 2012. Sibling relationships and influences in childhood and adolescence. J. Marriage Fam. 74, 913-30. doi: 10.1111/j.1741-3737.2012.01011.x

2. Furman, W., and Buhrmester, D. 1985. Children's perceptions of the qualities of sibling relationships. Child Dev. 56:448-61. *This questionnaire was translated to Hebrew by Anat Zaidman-Zait, Tel Aviv University and Dafna Regev, University of Haifa.

3. Leedham, A. T., Thompson, A. R., and Freeth, M. 2020. A thematic synthesis of siblings' lived experiences of autism: Distress, responsibilities, compassion and connection. Res. Dev. Disabil. 97:103547. doi: 10.1016/j.ridd.2019.103547

4. Orsmond, G. I., and Seltzer, M. M. 2007. Siblings of individuals with autism spectrum disorders across the life course. Ment. retard. dev. disabil. res. rev. 13:313-20. doi: 10.1002/mrdd.20171

5. Rum, Y., Zachor A, D., Armony, Y., Daniel, E., and Dromi, E. (2021b). Sibling Relationships in Families of Children With and Without Autism: Specificity and Commonality According to the Siblings' and the Mothers' Perspectives. Israeli Meeting for Autism Research (I-MAR) Available online at: https://www. youtube.com/watch?v=GkmXmqP_ZAk\&list=PLcKuhKMfYsYL8V8K-Y$\mathrm{HttGjJA7olusa2 \& index=5}$

6. Ben-Itzchak, E., Nachshon, N., and Zachor, D. A. 2018. Having siblings is associated with better social functioning in autism spectrum disorder. J. Abnorm Child Psychol. 47:921-31. doi: 10.1007/s10802-018-0473-z

7. Rum, Y., Zachor, D. A., and Dromi, E. (2021). Prosocial behaviors of children with autism spectrum disorder (ASD) during interactions with their typically developing siblings. Int. J. Behav. Dev. 45, 293-298. doi: 10.1177/0165025420971042

8. Shivers, C. M. 2019. Empathy and perceptions of their brother or sister among adolescent siblings of individuals with and without autism spectrum disorder. Res. Dev. Disabil. 92:103451. doi: 10.1016/j.ridd.2019.103451

SUBMITTED: 06 June 2021; ACCEPTED: 15 July 2021;

PUBLISHED ONLINE: 26 August 2021.

EDITED BY: Idan Segev, Hebrew University of Jerusalem, Israel

CITATION: Rum Y and Dromi E (2021) Kids on the Autism Spectrum and Their Siblings. Front. Young Minds 9:721197. doi: 10.3389/frym.2021.721197 

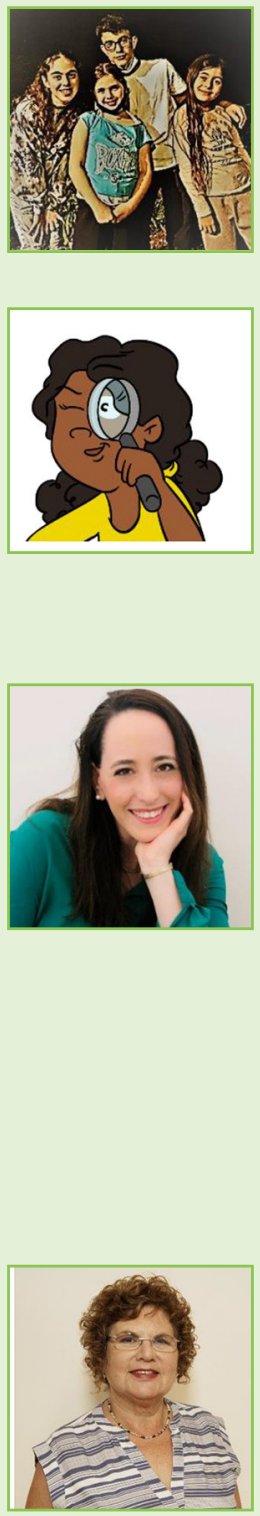

CONFLICT OF INTEREST: The authors declare that the research was conducted in the absence of any commercial or financial relationships that could be construed as a potential conflict of interest.

COPYRIGHT () 2021 Rum and Dromi. This is an open-access article distributed under the terms of the Creative Commons Attribution License (CC BY). The use, distribution or reproduction in other forums is permitted, provided the original author(s) and the copyright owner(s) are credited and that the original publication in this journal is cited, in accordance with accepted academic practice. No use, distribution or reproduction is permitted which does not comply with these terms.

\section{YOUNG REVIEWERS}

\section{SCHECHTMAN FAMILY, AGES: 8-13}

We are Uri, Mika, Roni, and Alona-cousins living in Tel Aviv and Gedera, and enjoy meeting for Friday dinners at our grandmother's house in Rehovot. We have many different interests, but all of us are interested in travel and science.

\section{METIAV, AGE: 14}

A student in 8th grade. Likes music, painting, photography, and Japanese culture.

\section{AUTHORS}

\section{YONAT RUM}

Dr. Yonat Rum is a postdoctoral researcher in the Autism Research Centre at the University of Cambridge. She focuses on empathy in autism and towards autistic individuals. Previously, at the Hebrew University of Jerusalem, she focused on the possible positive influences that growing up with a special-needs sibling has on the development of empathy. She completed her Ph.D. at Tel Aviv University, on the topic of kids on the autism spectrum and their siblings. Yonat has also directed support groups for siblings of kids on the autism spectrum, tutored kids on the autism spectrum, and was the professional manager of the Inclusion Coordinators Program - a post-graduate program for the training of inclusion coordinators for children with autism, at Tel Aviv University. *yonat.rumamail.huji.ac.il

\section{ESTHER DROMI}

Professor Esther Dromi is a Professor Emeritus at the Constantiner School of Education of Tel Aviv University. She earned her BA and MA degrees in Speech Pathology and Clinical Audiology at the School of Communication Disorders in Tel Aviv, and her Ph.D. in Child Language at Kansas University. On top of her research and teaching career of about 40 years, she has clinical experience working with young children with severe communication and language impairments. Professor Dromi has published several academic books in Hebrew and in English as well as many book chapters and about 70 research articles in leading international scientific journals. 